\title{
Portable X-Ray Fluorescence as a Rapid Technique for Surveying Elemental Distributions in Soil
}

\author{
Tanja Radu', \\ Simon Gallagher², \\ Brian Byrne, \\ Paul Harris ${ }^{3}$, \\ Seamus Coveney ${ }^{3}$, \\ Stephen McCarron ${ }^{3}$, \\ Tim McCarthy ${ }^{3}$, \\ and Dermot Diamond ${ }^{2}$ \\ ${ }^{1}$ Loughborough University, \\ Loughborough, United Kingdom \\ ${ }^{2}$ Dublin City University, \\ CLARITY, Dublin, Ireland \\ ${ }^{3}$ National University of Ireland \\ Maynooth, Ireland
}

\begin{abstract}
Case studies from two sites demonstrate how concentration distributions of hazardous contaminants can be rapidly measured and visualized using portable XRF (X-ray fluorescence) coupled with geostatistical interpolation tools. In this study, lead is used as an exemplar due to its well-known detrimental effect on human health through long-term exposure. A portable Thermo Scientific NITON X-ray fluorescence (XRF) instrument was used for real-time in-situ concentration measurements, which were linked to GPS coordinates of the sampling locations. A 52 point mixed sampling density survey was performed at a site near Maynooth, Co. Kildare, and a second 58 survey undertaken at Dublin City University (DCU). At Maynooth, high concentrations of $\mathrm{Pb}$ (above $110 \mathrm{mg} / \mathrm{kg}$ ) were found close to the site where a local canal meets a road. At the DCU site, results indicate high $\mathrm{Pb}$ concentrations (above $160 \mathrm{mg} / \mathrm{kg}$ ) near a busy main road. Geostatistical techniques were used to generate concentration prediction and critical threshold contour surfaces for both sites. Linked with GPS coordinates for each sampling location, this technology enables the distribution of multiple elements to be mapped over wide areas in a relatively short time.
\end{abstract}

Supplemental materials are available for this article. Go to the publisher's online edition of Spectroscopy Letters to view the supplemental file.

KEYWORDS heavy metals, soil pollution, XRF

\section{INTRODUCTION}

Contamination of soil by heavy metals is an important environmental issue of rapidly increasing research interest. ${ }^{[1]}$ In urban areas, soil provides recreational and aesthetic features that are deemed necessary for social development. However, due to the increase in human activities, such as traffic, ${ }^{[2]}$ and industry, ${ }^{[3]}$ extensive contamination with heavy metal pollutants in urban soils has occurred over decades. Human exposure to heavy metals results in an accumulation in the fatty tissue of the body, and this in turn affects the central nervous system and internal organs. ${ }^{[4,5]}$ Recent studies have shown that children are particularly at high risk due to higher
Received 30 July 2012; accepted 2 January 2013.

Address correspondence to Dermot Diamond, Dublin City University, CLARITY, Dublin, 9 Ireland. E-mail: Dermot.Diamond@dcu.ie 
levels of retention of these elements compared to older people. ${ }^{[6,7]}$ Furthermore, children tend to be more exposed to contamination sources such as soil, for example, during play, ${ }^{[7]}$ as ingestion of potentially toxic metals that have leached into topsoil can occur. Of particular significance is the concentration of lead $(\mathrm{Pb})$, as this has shown to impact the central nervous system and adversely affect IQ levels. ${ }^{[8]}$ Maximum allowed (or critical) values for $\mathrm{Pb}$ concentrations of soil should not exceed $300 \mathrm{mg} / \mathrm{kg} .{ }^{[9]}$

Recent developments in XRF technology have seen the emergence of battery-operated, field-deployable systems capable of in situ operation. These instruments initialize photo-electron fluorescence to perform fast and nondestructive analysis of environmental samples, including soils. It contains $80-\mathrm{MHz}$ real-time digital signal processing for in-field analysis, along with integrated USB and Bluetooth communications, which provide direct data transfer to the user's PC. Simultaneous analysis of up to 32 elements is possible and this, along with the capability of measuring solid samples directly (i.e., without digestion), significantly reduces the time required for sample characterization.

The XRF instrument can operate in several measurement modes, including bulk sample, thin sample, and $\mathrm{Pb}$ in paint testing. Environmental Protection Agency (EPA) Method $6200^{[10]}$ and National Institute for Occupational Safety and Health (NIOSH) Method ${ }^{[11]}$ are among the official methods that now employ $\mathrm{XRF}$ technology. The convenience and data richness of the techniques mean it is being increasingly used for the determination of metals in soils. ${ }^{[12-19]}$

A GPS feature allows the construction of spatial concentration maps, and in this study, we demonstrate how the analytical data can be integrated, analyzed, and visualized using reproducible geostatistical techniques. ${ }^{[20-22]}$ Here we specify a geostatistical methodology intended to suit the distributional properties of most of the 32 elements measured, at two study sites. Reproducibility should be ensured by only using open-source software. It is vital that the chosen methodology suits all of the study's objectives, and in this respect, a relatively sophisticated approach needs to be adopted, one that has been rarely applied in the literature.

\section{EXPERIMENTAL}

The portable XRF instrument used in this work was an XL3t 900 instrument obtained from Thermo
Scientific NITON, Winchester, UK. The operation method enables a simple "point and shoot" technique. Prior to sample analysis, an internal instrument calibration is performed. Typically, accuracy of the instrument is $0.1 \%$ but can vary from around this up to $5 \%$ to $6 \%$ in the case of magnesium $(\mathrm{Mg})$ and chromium (Cr). The error is matrix dependent and will depend on both the intensity of the element emission and the degree of coemission and of other elements. Precision (\% RSD) is usually in the range of $0-5 \%$, although it can be considerably higher, for example, for low-molecular-weight elements like aluminium ( $\mathrm{Al}$ ). For $\mathrm{Pb}$, the \% RE (accuracy) is typically ca. $0.1 \%$ and the precision ca. $0.5 \%$.

Two XRF sampling campaigns were conducted: (1) at the Dublin City University (DCU) campus in Dublin, Ireland (sample site, approximately $350,000 \mathrm{~m}^{2}$ ), and (2) at a sports field site in Maynooth, a small university town in Co. Kildare about $25 \mathrm{~km}$ west of central Dublin (sample site, approximately $10,000 \mathrm{~m}^{2}$ ). All sample locations were analyzed using the "soil mode" of the XRF instrument, where high- and low-resolution trials were performed on the DCU campus site. A 52-point mixed sampling density survey was used to analyze the Maynooth sports field site, while 58 sample locations were analyzed at the DCU campus site.

No specific, preplanned sampling strategies were employed, other than ensuring a reasonable spatial coverage of the two study sites (noting that each site has certain physical constraints where sampling is impossible). Here it should be noted that sample size and configuration directly influence the behavior (or reliability) of the subsequent geostatistical analyses. As such, their results (given in the section on "Geostatistical Modeling") should be viewed in context of the chosen sampling regime. In order to ensure the accuracy of the sampling locations, a differential GPS measurement was used to locate the positions of all the sample sites.

The XRF surveys of the DCU campus and the Maynooth sports field site were taken over 2-day periods in July and August 2010, respectively. A stainless steel spade was used to cut and temporarily remove the grass to expose the mineral-rich topsoil at a depth of $5-10 \mathrm{~cm}$. Removing the grass from the sample analyzed was advised by NITON representatives as it may interfere with fluorescence spectra. Each sample location was analyzed for 180 
seconds per sample. The fluorescence spectra were generated by a peltier-cooled solid-state photodiode detector and downloaded to a spreadsheet for further processing using Bluetooth wireless communications.

\section{SAMPLING RESULTS AND DISCUSSION}

\section{Elemental Data}

At each sampling site, measurements for a total of 32 soil contaminants were taken. This included measurements for main anthropogenic metals, such as arsenic (As), cadmium (Cd), cobalt (Co), $\mathrm{Cr}$, copper $(\mathrm{Cu})$, mercury $(\mathrm{Hg})$, nickel $(\mathrm{Ni}), \mathrm{Pb}$, vanadium (V), and zinc ( $\mathrm{Zn}$ ), all of which are closely associated with human activity and known to pose risks to human health. For each element, the XRF provides a measurement and an associated error on this measurement. Measurement error can be integrated into the geostatistical analysis (see the section on "Geostatistical Methodology: Step by Step"). The raw data are given as attachment ("Portable_XRF_Sampling_DCU_Maynooth.xlsx") so the reader can gauge XRF data quality. Here relatively high measurement errors are observed for many of the sampled elements. Some elements, notably $\mathrm{As}, \mathrm{Co}, \mathrm{Cu}, \mathrm{Hg}$, and $\mathrm{Ni}$, showed concentrations to be around or below the limit of detection (LOD) in every sample.

\section{Lead Data}

For this study, we focus on modeling the spatial distribution of $\mathrm{Pb}$, but this could easily be extended to encompass all 32 contaminants (following the same or a similar methodology). For the Maynooth and DCU sites, 22 (from 52) and 8 (from 58) samples resulted in $\mathrm{Pb}$ concentrations below the LOD, respectively. These are valid observations and it is common practice to assign them an arbitrary value to half the LOD of the measuring device. ${ }^{[23,24]}$ However, in this study, such observations were arbitrarily set to zero, as the instrument's LOD for $\mathrm{Pb}$ was unknown.

Attention is given to soil $\mathrm{Pb}$ as it is a significant source of human exposure to $\mathrm{Pb}$, especially among children. ${ }^{[8]}$ Anthropogenic sources of $\mathrm{Pb}$ include its use in ammunition, water supply pipes, roofing materials, and batteries; in the manufacture of glass, pottery, and ceramics; and as an additive to paint, petrol, and pesticides. ${ }^{[25]}$ Furthermore, leaded petrol combustion, smelting, and $\mathrm{Pb}$ metal works can emit $\mathrm{Pb}$ particles to the atmosphere that in turn can be deposited in soils. Pb can also be deposited in soils due to the dumping of lead-containing materials and the weathering of building materials. Geogenic sources of $\mathrm{Pb}$ in Dublin and surrounding areas can relate to natural background and natural anomalies.

\section{GEOSTATISTICAL MODELING Objectives and Limitations}

A study into the spatial process of the $\mathrm{Pb}$ data at both sampling sites is undertaken via a geostatistical methodology intended to suit the distributional properties of most of the 32 elements measured, and not just $\mathrm{Pb}$. We naïvely assume simple, continuous spatial processes, whereas it is much more likely that each process is sometimes discontinuous, operating at different spatial scales and driven by various artificial, environmental, and historical factors. Such complex urban processes require a substantive piece of model development that is beyond the aims of this study. That said, assuming and modeling a continuous process should still provide insights into the behavior of the Pb data, broadly identifying areas of high soil contamination and concern. The geostatistical outputs can be viewed as preliminary, benchmark results, where subsequent modeling work, coupled with a second more targeted sampling campaign, would aim to improve on them. The design of a second sampling campaign can be guided or optimized according to the observed geostatistical properties of this study's (the pilot study) data. ${ }^{[26]}$

\section{Spatial Prediction with Kriging}

The objectives of a geostatistical analysis can generally be attributed to one of the following: (1) the estimation and modeling of spatial dependence in the data via the variogram, (2) spatial prediction (kriging) at unsampled sites and estimating associated measures of uncertainty, (3) data simulation, and (4) sample design. For this study, we are only 
concerned with prediction. ${ }^{[27]}$ There are numerous kriging algorithms to choose from, largely depending on the modeling objective, the particular properties of data being modeled, and whether or not a univariate or multivariate analysis is required. ${ }^{[28]}$ In this univariate study, empirical maximum likelihood kriging (EMLK) ${ }^{[21,22]}$ is chosen, where applications of EMLK are supplemented by simpler applications of ordinary kriging (OK) and kriging with a trend model $(\mathrm{KT})^{[28]}$ for context, comparison, and model development. Restricted maximum likelihood (REML) ${ }^{[29]}$ is used to find the variogram parameters that are required to calibrate all of the applied kriging algorithms.

\section{Empirical Maximum Likelihood Kriging}

EMLK is a sophisticated extension of $\mathrm{OK} / \mathrm{KT}$ where more efficient results are obtained by solving the prediction problem in the Gaussian domain via a normal scores transform of the sample data. Furthermore, a Bayesian component in EMLK ensures conditionally unbiased results where a posterior predictive distribution is found at all target locations $\mathrm{x}$. For a variable $z$, the mean of the posterior distribution is taken as the EMLK prediction $\hat{z}_{E M L K}(X)$ and the variance of the posterior distribution $\sigma_{E M L K}^{2}(X)$ can be used to assess the uncertainty of the EMLK prediction. Details of the EMLK algorithm can be found in refs. [20-22], where an open-source FORTRAN program (EMLK2D.F95) is available that provides EMLK predictions on a grid. ${ }^{[22]}$

EMLK is chosen to model the XRF study data, in so much it is (1) advocated for small data sets; (2) advocated for nonnormal data sets, including those with observations below the LOD; ${ }^{[20]}$ (3) able (via its Bayesian construction) to provide a more realistic approach to prediction uncertainty than that found in many basic algorithms such as $\mathrm{OK}$ or $\mathrm{KT}^{[30-32]}$ (and, in turn, can provide reliable estimates of risk for exceeding a given contamination threshold); and (4) it is open source.

There are few credible alternatives to EMLK that (1) suit the properties of our sampled data (i.e., points (1) and (2), above), (2) fulfill our modeling objectives (i.e., point (3), above), and (3) has an open-source version of its code (i.e., point (4), above). Indicator kriging ${ }^{[33]}$ would generally provide a reasonable alternative, but its variography can suffer when sample size is small. There exists a Bayesian cokriging approach ${ }^{[34]}$ that is useful in that all 32 elements could be predicted simultaneously, but specifying and fitting such a sophisticated model requires considerable statistical expertise. Observe that although we view our EMLK-based study as preliminary, EMLK is still a relatively sophisticated approach, where we still aim to model the data as accurately as possible.

\section{Geostatistical Methodology: Step by Step}

The steps of our geostatistical analyses are conducted as follows:

1. Observe the spatial distribution of the raw data and place this data in context (e.g., map with relevant roads, waterways, railways, buildings) (Fig. 1).

2. Transform the raw data to normality using normal scores (Figs. 2A-B and 3A-B).

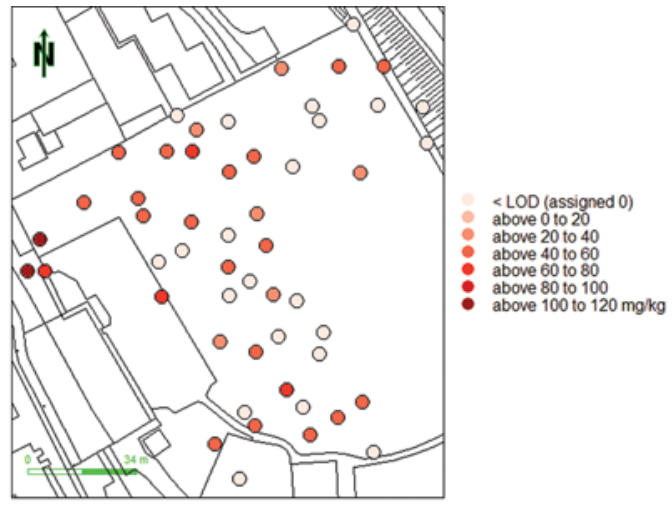

(A)

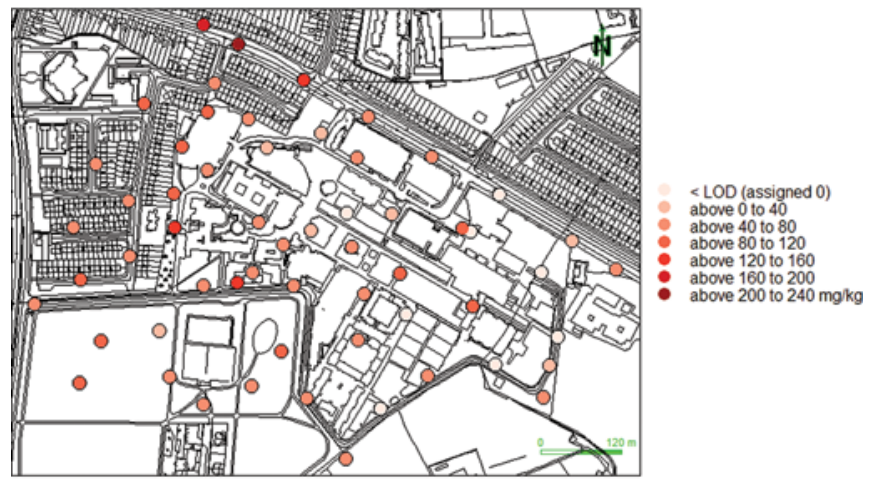

(B)

FIGURE 1 Spatial distribution of raw data $(\mathrm{mg} / \mathrm{kg})$ for $(A)$ Maynooth and (B) DCU sites. (color figure available online.) 


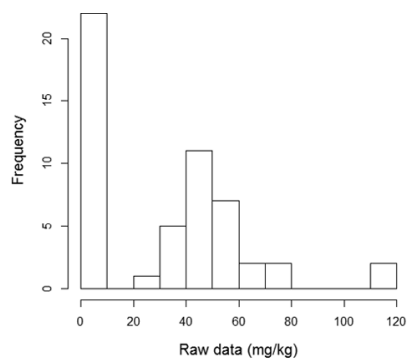

(A)

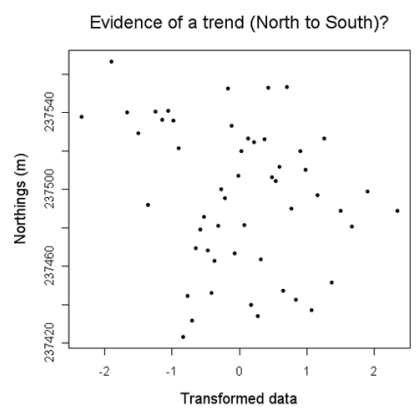

(C)

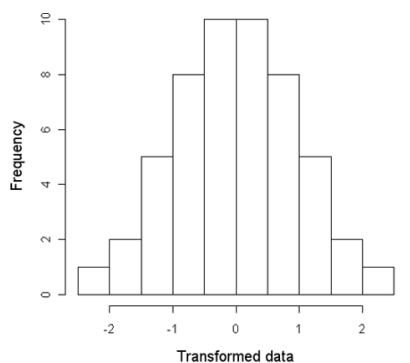

(B)

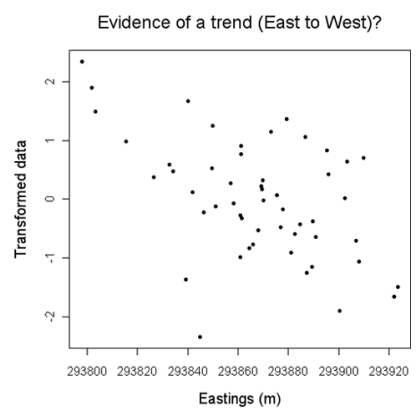

(D)
FIGURE 2 Exploratory data analysis for Maynooth site $(n=52)$ : histograms of $(A)$ raw $(\mathrm{mg} / \mathrm{kg})$ and $(B)$ transformed data; (C) and (D) projections of transformed data with coordinates (for evidence of a KT-type model).

3. In the transformed space assess evidence of a spatial trend to indicate whether an OK- or KT-type approach should be specified for the EMLK run. This is achieved simply, by plotting the transformed data against the coordinate data (one at a time) and looking for a relationship (Figs. 2C-D and 3C-D).

4. In the transformed space, use REML to find the variogram and (if necessary) the trend model parameters (i.e., only if KT adopted) that need to be specified for the EMLK run (Fig. 4). When specifying the REML fit, use the mean of the observed data measurement errors to fix (not estimate) the nugget variance variogram parameter. That is, assume a stationary measurement error that is fully accounted for in the nugget variance. This ensures that measurement error is reflected in the spread of each predictive distribution of step 6. In all cases, fit only exponential variogram models, and for context, present the REML model fits with a classic (estimated not modeled) method of moments variogram. ${ }^{[28]}$

5. In the transformed space, use basic OK (or KT) as a (computationally simpler) surrogate for its EMLK form to find an optimal prediction neighborhood for the EMLK run (Fig. 5). Here, a series of leave-one-out root mean squared prediction errors (RMSPE) are found for different neighborhood

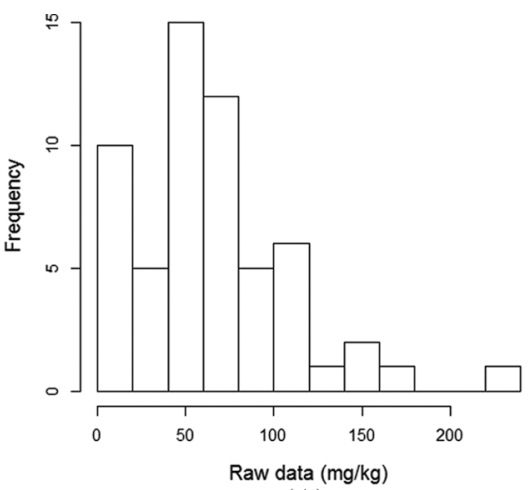

(A)

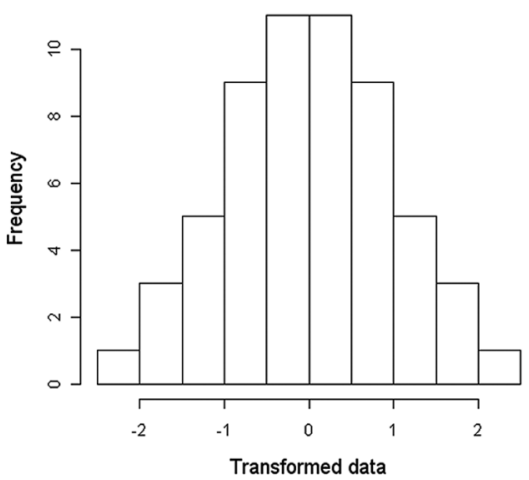

(B)

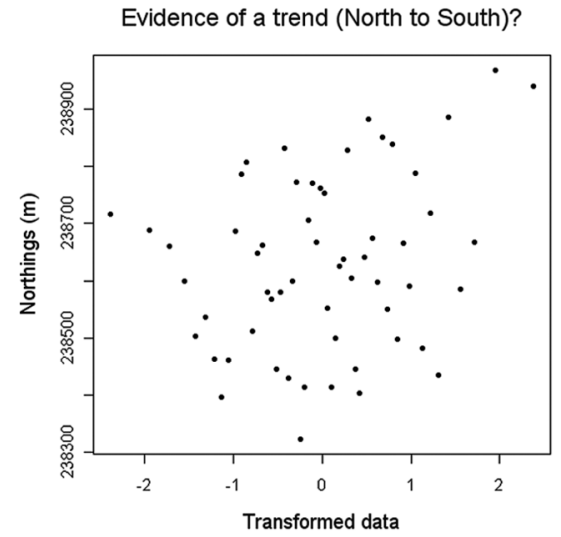

(C)

Evidence of a trend (East to West)?

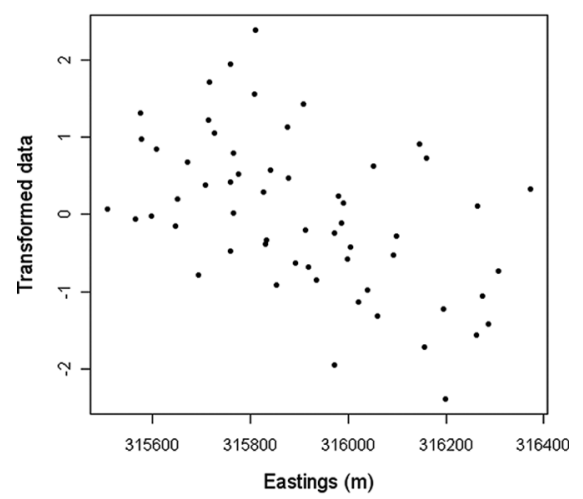

(D)

FIGURE 3 Exploratory data analysis for DCU site $(n=58)$ : histograms of (A) raw $(\mathrm{mg} / \mathrm{kg})$ and (B) transformed data; (C) and (D) projections of transformed data with coordinates (for evidence of a KT-type model). 


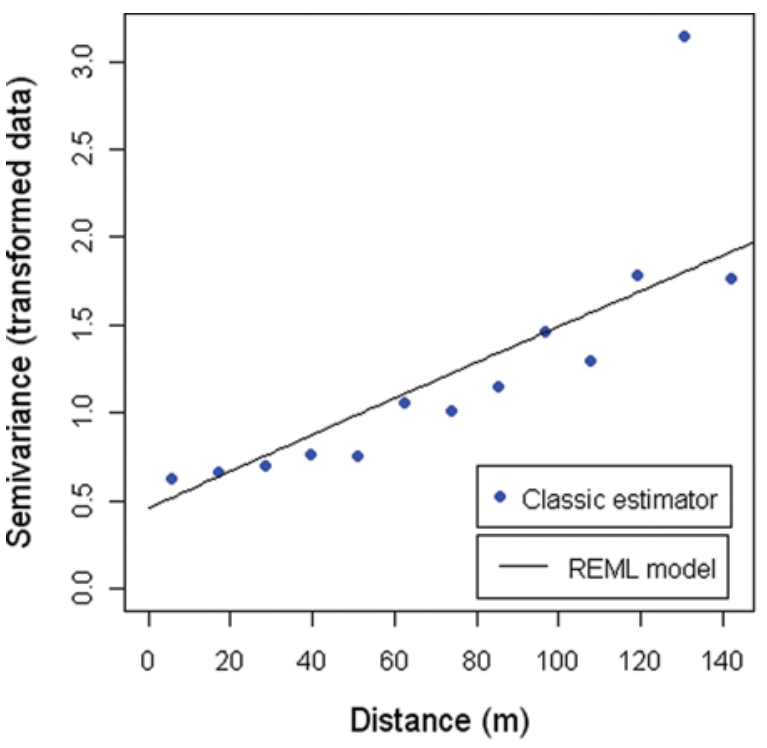

(A)

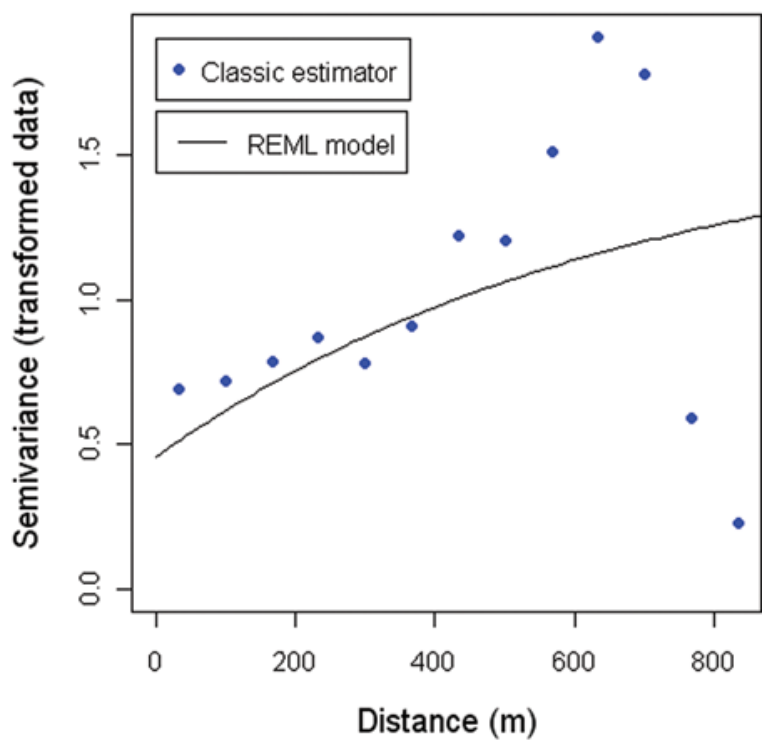

(B)

FIGURE 4 Variography for (A) Maynooth and (B) DCU sites. All variograms using transformed data where the REML fits are specified with a constant trend and exponential model. For Maynooth site, nugget variance fixed at 0.456 squared units, partial sill estimated at 31.64 squared units, and range estimated at $\mathbf{3 0 0 9}$ meters. For DCU site, nugget variance fixed at $\mathbf{0 . 4 5 5}$ squared units, partial sill estimated at 1.141 squared units, and range estimated at 661.6 meters. (color figure available online.)

sizes. An optimal neighborhood is one that corresponds to the smallest RMSPE.

6. Use the outputs from steps $2-5$ to calibrate the EMLK algorithm to predict on a grid. Use the (back-transformed) posterior means to populate a prediction surface (Figs. 6A and 7A). Define an example critical cut-off for concentrations and find a "risk of exceedance" surface using the full

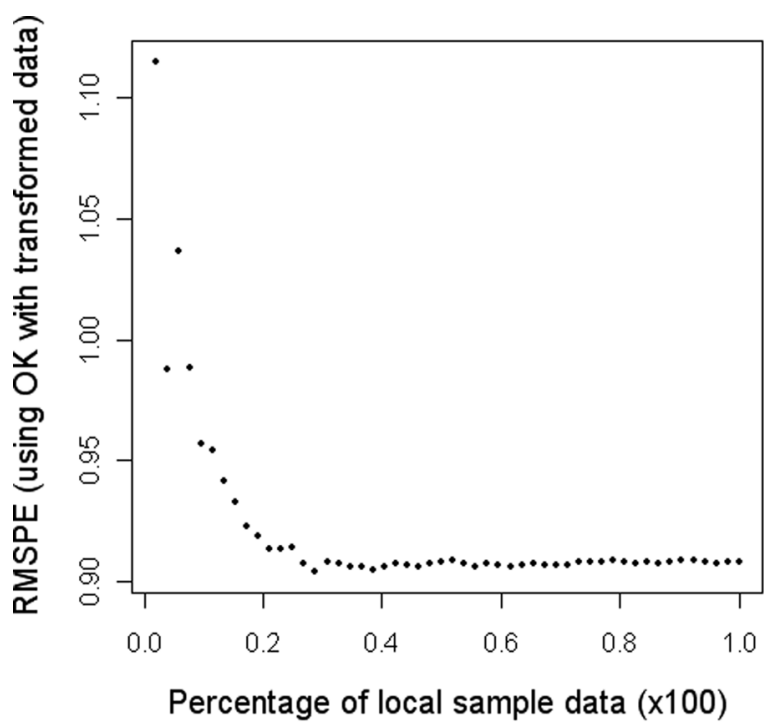

(A)

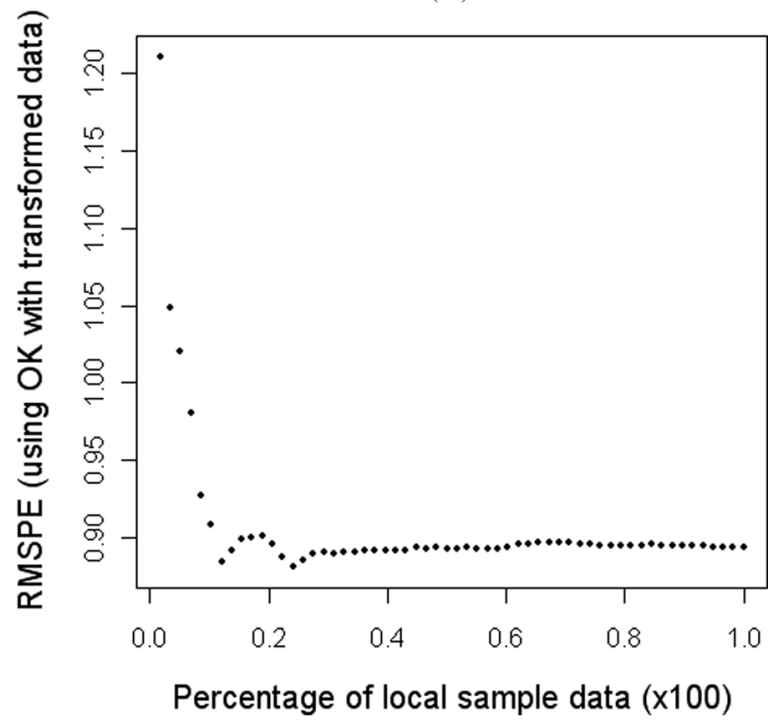

(B)

FIGURE 5 Kriging neighborhood functions with respect to RMSPE (i.e., prediction accuracy for different neighborhood sizes using OK with transformed data) at (A) Maynooth and (B) DCU sites. Minimums taken at neighborhood sizes of $N=15(28.8 \%$ of sample data) and $N=14$ (24.1\% of sample data), respectively.

posterior predictive distributions that are specific to each grid point (Figs. 6B and 7B).

All exploratory analyses, REML variogram fits, and basic OK/KT runs are conducted within the open-source R statistical computing environment. ${ }^{[35]}$ Here the gstat $^{[36]}$ and the geoR ${ }^{[29]}$ geostatistical packages are extensively utilized. Postprocessing of the gridded EMLK2d. F95 output data for the contoured surfaces is also conducted in $\mathrm{R}$ using the $\mathrm{sp}^{[37]}$ spatial data package. The contoured surfaces could have been presented using ArcGIS (ESRI 


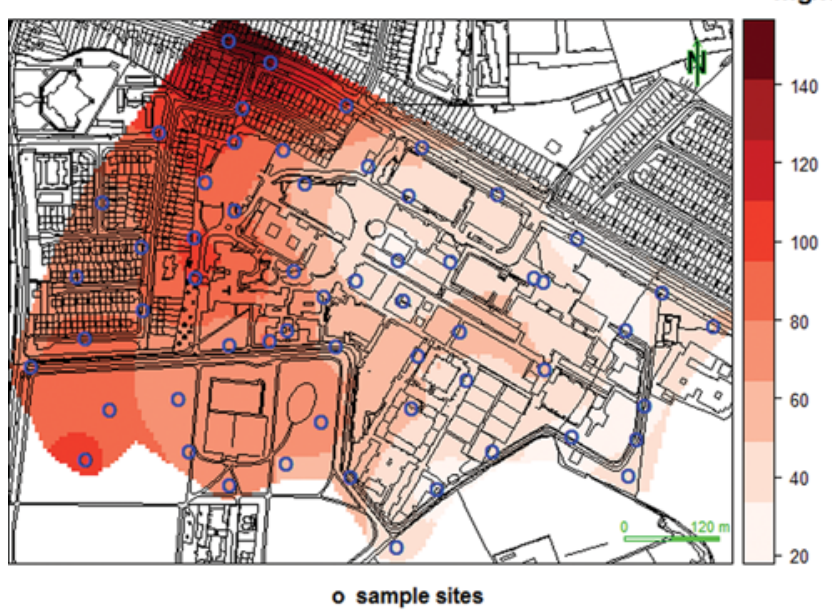

(A)

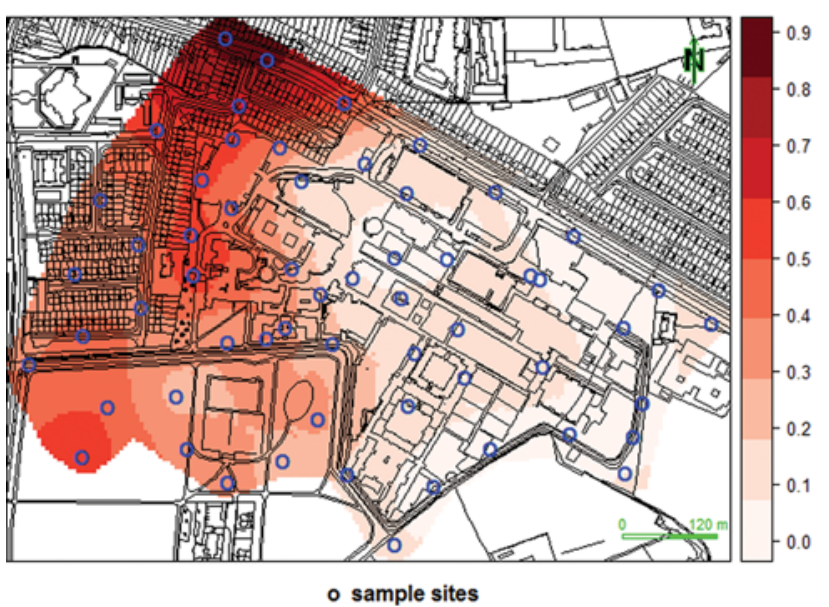

(B)

FIGURE 7 EMLK prediction $(\mathrm{mg} / \mathrm{kg})(\mathrm{A})$ and risk of exceedance (B) surfaces for DCU site. For the risk surface, an arbitrary cut-off of $80 \mathrm{mg} / \mathrm{kg}$ is used for demonstration purposes only. (color figure available online.)

\section{Geostatistical Analysis for $\mathrm{Pb}$ at the Maynooth Sports Field Site}

For the Maynooth sports field site, the spatial coverage of data is reasonable (Fig. 1A) and as such, no adverse modeling effects due to sample configuration are expected. Most observations are taken in the sports field, although three observations to the west are outside of the sports field and are taken on grass verges of a nearby "no-through" road (used mainly for parking for a train station to the south). However, these three locations are also in the path of occasional flooding from the nearby canal (which is still in use and has a slipway adjoining the road). It is therefore not surprising that two of these three observations also 
produce the two highest $\mathrm{Pb}$ concentrations. A key difficulty with modeling this data is that sample size is small, and $42 \%$ of the observations have values set to zero (i.e., they lie below the LOD). However, the benefit of applying a normal scores transform to this data is that a Gaussian distribution is ensured regardless of the shape of the raw data (Fig. 2A-B). This, in turn, ensures certain optimality in the EMLK results provided that the (difficult) back-transforms are reasonable.

From Fig. 2D, there is evidence of an east-to-west, low-to-high trend in the data. In this respect, a KT model with a first-order polynomial trend fit (of the coordinate data) was applied. The resulting residual variogram depicted pure nugget (random) variation (not shown), indicating that the trend fit itself would suffice as a valid model for this data. OK (i.e., kriging without a trend fit) gave similar results to the simple trend fit and, in this case, was selected as the basic kriging form. The transformed data variography is given in Fig. 4A. As the identified trend in data was not filtered out, the variography has a characteristic unbounded and increasing nature.

The OK neighborhood function for this transformed data results in an optimum of the nearest 15 observations (Fig. 5A) and is specified in this data's EMLK run. The EMLK prediction surface is given in Fig. 6A, where high $\mathrm{Pb}$ concentrations are found in the west, near to the road and canal slipway. The EMLK "risk of exceedance" surface (Fig. 6B) largely mimics that of the $\mathrm{Pb}$ prediction surface, where the risk of exceeding the chosen cut-off of $80 \mathrm{mg} / \mathrm{kg}$ is relatively low everywhere.

\section{Geostatistical Analysis for $\mathrm{Pb}$ at the DCU Campus Site}

For the DCU campus site, the spatial coverage of data is also good (Fig. 1B). Most observations were taken within the DCU campus, but some observations were taken in a nearby residential area to the west and in green areas to the south. The two highest $\mathrm{Pb}$ concentrations lie on the edge of the sampled area to the north, next to a busy main road. From Fig. 3C-D, there is little evidence of a trend in this data, and as such, OK was also chosen as the basic kriging form. In this case, the REML variogram fit strongly differs from the classic variogram (Fig. 4B). The OK neighborhood function (Fig. 5B) yields an optimum of the nearest 14 observations and is specified in this data's EMLK model. The EMLK prediction surface is given in Fig. 7A, where high $\mathrm{Pb}$ concentrations are depicted in the north beside the (first) busy main road. Other areas of high $\mathrm{Pb}$ concentration can be found to the west, near a second main road. Again, the EMLK "risk of exceedance" surface (Fig. 7B) largely mimics that of the prediction surface, where the risk of exceeding a cut-off of $80 \mathrm{mg} / \mathrm{kg}$ is relatively high in areas of high $\mathrm{Pb}$ concentrations.

\section{Relative Accuracy of the EMLK Outputs}

Both EMLK and OK provide predictions and prediction variances at any location, but they differ in that the former is able to provide more (locally) realistic prediction variances and associated estimates of risk than the latter. ${ }^{[21]}$ This difference primarily relates to a modeling assumption in $\mathrm{OK}$ that the variability in the sample data is stationary across space. ${ }^{[30-32]}$ Thus, a simple assessment of the local behavior of the EMLK and OK variances is to relate them to actual local variances, where ideally some relationship is expected. This assessment is conducted in order to validate the choice of EMLK as our study kriging method.

In this respect, actual local variances are found using a geographically weighted (GW) approach, ${ }^{[39,40]}$ which for sample data denoted by $\alpha=1, \ldots, n$ can be defined as $s^{2}(\mathrm{x})=\sum_{\alpha=1}^{n} w_{\alpha}\left(z\left(\mathrm{x}_{\alpha}\right)-m(\mathrm{x})\right)^{2} / \sum_{\alpha=1}^{n} w_{\alpha}$, where $m(\mathrm{x})=\sum_{\alpha=1}^{n} w_{\alpha} z\left(\mathrm{x}_{\alpha}\right) / \sum_{\alpha=1}^{n} w_{\alpha}$ is a GW mean, and where the weights $w_{\alpha}$ accord to some distance-decay kernel function. For this study, we specify a bi-square kernel with an adaptive bandwidth set to the same neighborhood size as that used in the EMLK and OK runs.

As the GW mean is itself a simple spatial predictor, it is also compared to the EMLK and OK predictions to provide a neat symmetry in this model comparison, where grid outputs from the two complementary GW models are compared to those from EMLK and OK. Scatterplot matrices and correlation coefficients are used for this comparison (Fig. 8). As the grid outputs total over 30,000 points for each study site, a random subset of about 600 grid points is used to facilitate a clearer visual interpretation. 

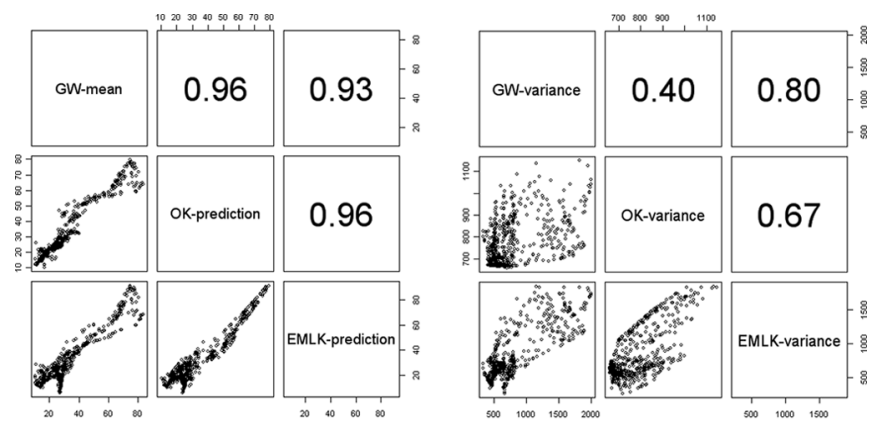

(A)
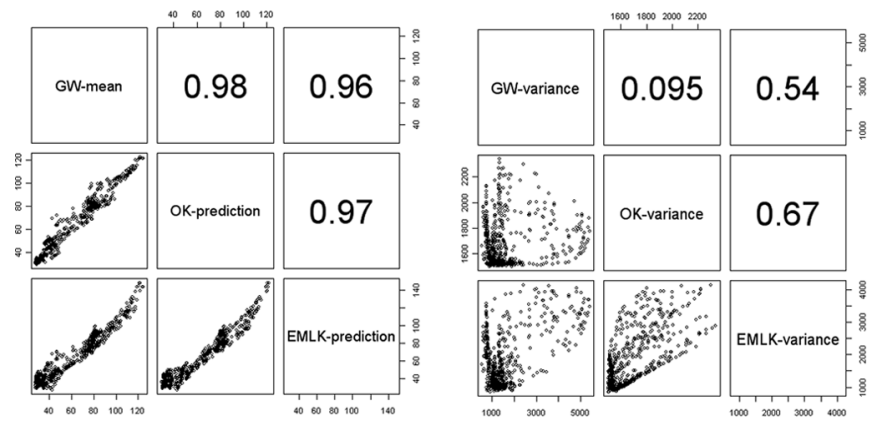

(B)

FIGURE 8 Matrices of scatterplots and associated correlation coefficients for relative performance of EMLK predictions $(\mathrm{mg} /$ $\mathrm{kg}$ ) and variances, with respect to (i) OK predictions $(\mathrm{mg} / \mathrm{kg})$ and variances (left) and (ii) GW means ( $\mathrm{mg} / \mathrm{kg}$ ) and $\mathrm{GW}$ variances (right), for (A) Maynooth and (B) DCU sites.

For both study sites, there is little to choose between the GW means and the OK and EMLK predictions. Thus, all three models are equally valid. This similarity between predictors is commonplace ${ }^{[26]}$ where a sophisticated predictor (i.e., some kriging model) is often only marginally more accurate than an unsophisticated one (i.e., some nonparametric smoother such as the GW mean).

As expected, key differences arise with respect to assessments of local uncertainty, where the EMLK variances more strongly correlate with the GW variances than the OK variances do (and, as such, are able to better reflect the local properties of the sample data). However, this does not entail that the EMLK and OK variances do not correlate well with each other, as both variance estimates will have similar properties from their underlying geostatistical design. Here they should still reflect areas of under- and oversampling (giving high and low prediction variances, respectively). Observe also that unlike the kriging models, the GW means do not come with associated estimates of prediction uncertainty (as there is no underlying model).

\section{BENEFITS OF USING PORTABLE XRF APPROACH}

The primary benefit of the XRF approach is the ability to obtain multielement analytical data from solid samples like soil without having to employ tedious wet-chemical digestion, in contrast to commonly employed analytical techniques like AAS, ICP, or chromatographic methods. Furthermore, the approach is inherently nondestructive and samples are available for subsequent analysis by other techniques that may offer better analytical characteristics like LOD or accuracy/precision. As such, portable $\mathrm{XRF}$ is an ideal technique for rapid screening of large areas and identifying locations that could be classified as pollution "hot spots" that require further detailed investigation. In addition, the ability to link the analytical data to GPS coordinates of the sampling locations allows spatial distributions and trends to be rapidly visualized and identified using geostatistical techniques. For example, at the DCU site, there is a clear trend where the $\mathrm{Pb}$ levels apparently increase toward local roads that bear heavy traffic loads. Such trends lead to debate about the underlying reasons for their existence. In this case, the implication is that the higher $\mathrm{Pb}$ levels are a consequence of the traffic, due to the extensive use of lead-bearing fuel for many years. Validating this claim of course would require more extensive research and referencing to similar studies worldwide. XRF enables interesting trends like this to be discovered as the sites can be surveyed much more quickly than using conventional methods. Furthermore, it also enables "hot spots" to be uncovered, which assists with second-phase sampling strategies that home in on these hot regions; these samples are then analyzed with more sensitive techniques like ICP that can provide very accurate and precise data at much higher sensitivities. The availability of portable XRF with integrated GPS makes this type of pollution screening study much simpler to perform, and we can expect the volume of spatially located analytical information to rise rapidly in the coming years, which in turn facilitates more certain identification of the sources of pollution in the environment.

\section{CONCLUSIONS}

Portable XRF with integrated GPS opens the way to obtaining multielement information that is spatially 
located and compatible with advanced statistical tools and map-based graphical visualization. Such studies enable trends in distribution to be rapidly identified and the underlying sources deduced. In the cases presented in this study, $\mathrm{Pb}$ distribution at two sites has been explored and spatial trends identified. These in turn have been tentatively linked in one case to traffic on local roads and in the second case to water coming from a local canal. We anticipate many more studies of this type, in which portable XRF is used to rapidly screen large sites to identify possible pollution hot spots and trends in the elemental distributions.

\section{ACKNOWLEDGMENTS}

For Harris, Coveney, and McCarthy, the research presented in this paper was funded by a Strategic Research Cluster grant (07/SRC/I1168) by the Science Foundation Ireland under the National Development Plan. We also acknowledge support from Science Foundation Ireland under grant 07/CE/I1147"CLARITY: Centre for Sensor Web Technologies" and from the Irish EPA under the STRIVE Programme (EPA-2007-INF-4-S5).

\section{REFERENCES}

1. Ajmone-Marsan, F.; Biasioli, M. Trace elements in soils of urban areas. Water Air Soil Poll. 2010, 213(1-4), 121-143.

2. Govil, P.; Sorlie, J.; Murthy, N.; Sujatha, D.; Reddy, G.; Rudolph-Lund, K.; Krishna, A.; Rama Mohan, K. Soil contamination of heavy metals in the Katedan Industrial Development Area, Hyderabad, India. Environ. Monit. Assess. 2008, 140, 313-323.

3. Guney, M.; Onay, T. T.; Copty, N. Impact of overland traffic on heavy metal levels in highway dust and soils of Istanbul, Turkey. Environ. Monit. Assess. 2010, 164, 101-110.

4. Sharma, R. K.; Agrawal, M.; Marshall, F. Heavy metal contamination of soil and vegetables in suburban areas of Varanasi, India. Ecotoxicol. Environ. Safety 2007, 66, 258-266.

5. Nriagu, J. O. A silent epidemic of environmental metal poisoning? Environ. Pollution 1988, 50, 139-161.

6. De Miguel, E.; Iribarren, I.; Chacón, E.; Ordonez, A.; Charlesworth, S. Risk-based evaluation of the exposure of children to trace elements in playgrounds in Madrid (Spain). Chemosphere 2007, 66, 505-513.

7. Ljung, K.; Oomen, A.; Duits, M.; Selinus, O.; Berglund, $M$. Bioaccessibility of metals in urban playground soils. J. Environ. Sci. Health 2007, A42, 1241-1250.

8. Mielke, H. W.; Gonzales, C. R.; Smith, M. K.; Mielke, P. W. The urban environment and children's health: soils as an integrator of lead, zinc, and cadmium in New Orleans, Louisiana U. S.A. Environ. Res. A 1999, 81, 117-129.

9. Toprak Kirliliginin Kontrolü Yönetmeligi. In T.M.o. E.a. Forestry; Resmi, T. C., Ed.; Gazete: Ankara, 2005; 13.

10. EPAMethod6200: field-portable X-ray fluorescence spectrometry for the determination of elemental concentrations in soil and sediment. Available from: http://www.epa.gov/SW-846/pdfs/6200.pdf (accessed May 17, 2013).
11. NIOSH Method 7702: lead by field portable XRF. Available from: http://www.cdc.gov/niosh/nmam/pdfs/7702.pdf. (accessed May 17, 2013).

12. Bernick, M. B.; Kalnicky, D. J.; Prince, G.; Singhvi, R. Results of field-portable $\mathrm{X}$-ray fluorescence analysis of metal contaminants in soil and sediment. J. Hazard. Mater. 1995, 43, 101-110.

13. Carr, R.; Zhang, C. S.; Moles, N.; Harder, M. Identification and mapping of heavy metal pollution in soils of a sports ground in Galway City, Ireland, using a portable XRF analyser and GIS. Environ. Geochem. Health 2008, 30, 45-52.

14. Clark, S.; Menrath, W.; Chen, M.; Roda, S.; Succop, P. Use of a field portable X-ray fluorescence analyzer to determine the concentration of lead and other metals in soil samples. Ann. Agric. Environ. Med. 1999, 6, 27-32.

15. Mäkinen, E.; Korhonen, M.; Viskari, E.-L.; Haapamäki, S.; Järvinen, M.; Lu, L. Comparison of XRF and FAAS methods in analysing CCA contaminated soils. Water Air Soil Pollut. 2005, 171, 95-110.

16. Shefsky, S. Comparing field portable X-ray fluorescence (XRF) to laboratory analysis of heavy metals in soil. Presented at the International Symposium of Field Screening Methods for Hazardous Wastes and Toxic Chemicals, Las Vegas, Nevada, USA, January 29-31, 1997. Available from: http://www.epa.gov/tio/download/ char/dataquality/ sshefsky02.pdf. (accessed May 17, 2013).

17. Markey, A.; Clark, C.; Succop, P.; Roda, S. Determination of the feasibility of using a portable X-ray fluorescence (XRF) analyzer in the field for measurement of lead content of sieved soil. J. Environ. Health 2008, 70, 24-29.

18. Shefsky, Stephen, NITON Corporation. Comparing field portable $X$-ray fluorescence (XRF) to laboratory of heavy metals in soil. http://www.epa.gov/tio/download/char/dataquality/sshefsky02.pdf. (accessed May 17, 2013).

19. Radu, T.; Diamond, D. Comparison of soil pollution concentrations determined by AAS and portable XRF techniques. J. Hazard. Mater. 2009, 171, 1168-1171

20. Pardo-Igúzquiza, E.; Chica-Olmo, M. Interpolation and mapping of probabilities for geochemical variables exhibiting spatial intermittency. Appl. Geochem. 2005, 20, 157-168.

21. Pardo-Igúzquiza, E.; Dowd, P. A. Empirical maximum likelihood kriging: the general case. Math. Geol. 2005, 37, 477-492.

22. Pardo-Igúzquiza, E.; Dowd, P. A. EMLK2D: a computer program for spatial estimation using empirical maximum likelihood kriging. Computers Geosci. 2005, 31(3), 361-370.

23. Woodside, G.; Kocurek, D. Environmental, Safety, and Health Engineering; Wiley: New York, 1997.

24. Orton, T. G.; Rawlins, B. G.; Lark, R. M. Using measurements close to a detection limit in a geostatistical case study to predict selenium concentration in topsoil. Geoderma 2009, 152, 269-282.

25. Davies, B. E. Lead. In Heavy Metals in Soils; Alloway, B. J., Ed.; Blackie: Glasgow \& London, 1990.

26. Brus, D. J.; Heuvelink, G. B. M. Optimization of sample patterns for universal kriging of environmental variables. Geoderma 2007, 138, 86-95.

27. Matheron, G. Principles of geostatistics. Econ. Geol. 1963, 58, 1246-1266.

28. Chilès, J. P.; Delfiner, P. Geostatistics - Modelling Spatial Uncertainty; Wiley: New York, 1999. 695 pp.

29. Ribeiro, P. J.; Diggle, P. J. geoR: a package for geostatistical analysis. $R$ News 2001, 1, 15-18.

30. Journel, A. G. Geostatistics: models and tools for the earth sciences. Math. Geol. 1986, 18, 119-140.

31. Switzer, P. The spatial variability of prediction errors. In Geostatistics Troia, 92; Soares, A., Ed.; Kluwer Academic Publishers: The Netherlands, 1993; 261-272.

32. Heuvelink, G. B. M.; Pebesma, E. J. Is the ordinary kriging variance a proper measure of interpolation error? In The Fifth International Symposium on Spatial Accuracy Assessment in Natural Resources and Environmental Sciences; Melbourne, Australia, July 10-12, 2002; Hunter, G., Lowell, K., Eds.; Melbourne: RMIT University, 2002; 179-186. 
33. Goovaerts, P. AUTO-IK: a 2D indicator kriging program for the automated non-parametric modeling of local uncertainty in earth sciences. Computers Geosci. 2009, 35, 1255-1270.

34. Finlay, A. O.; Banerjee, S.; Carlin, B. P. spBayes: An R package for univariate and multivariate hierarchical point-referenced spatial models. J. Statistical Sci. 2007, 19(4).

35. Ihaka, R.; Gentleman, R. R. A language for data analysis and graphics. J. Computat. Graph. Statistics 1996, 5, 299-314.

36. Pebesma, E. J. Multivariate geostatistics in S: the gstat package. Computers Geosci. 2004, 30, 683-691.
37. Pebesma, E.; Bivand, R. Classes and methods for spatial data in R. $R$ News 2005, 5(2), 9-13.

38. Quantum GIS. http://www.qgis.org/index.php. (accessed May 17, 2013).

39. Brunsdon, C.; Fotheringham, A. S.; Charlton, M. E. Geographically weighted summary statistics-a framework for localised exploratory data analysis. Computers Environ. Urban Syst. 2002, 26, 501-524.

40. Bivand, R.; Yu, D. spgwr R package. Available from: http:// cran.r-project.org/web/packages/spgwr/index.html. (accessed May 17, 2013). 
Copyright of Spectroscopy Letters is the property of Taylor \& Francis Ltd and its content may not be copied or emailed to multiple sites or posted to a listserv without the copyright holder's express written permission. However, users may print, download, or email articles for individual use. 